IRA-International Journal of Technology \& Engineering ISSN 2455-4480

Proceedings of the

International Conference on Science \& Engineering for Sustainable Development (2017)

Pg. no. 340-351

Published by: Institute of Research Advances https://research-advances.org/index.php/IRAJTE

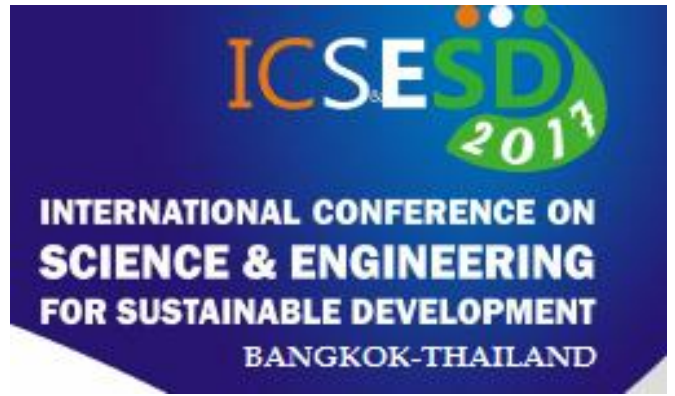

\title{
Potential of Shrouded Micro Wind Turbine
}

\author{
Kishor R. Sontakke*1, Samir J. Deshmukh ${ }^{2}$, Sandip B. Patil ${ }^{3}$ \\ ${ }^{1}$ PL Institute of Technology, Buldhana,(MS) Inida \\ ${ }^{2}$ PRM Institute of Technology and Research, Badnera-Amravati(MS) India \\ ${ }^{3}$ Bhujbal Knowledge City, Nashik(MS), India
}

Type of Review: Originality Check \& Peer Review under the responsibility of the Scientific Committee of the Conference and The Institution of Engineers (India). DOI: http://dx.doi.org/10.21013/jte.ICSESD201732

\section{How to cite this paper:}

Sontakke, K., Deshmukh, S., Patil, S. (2017). Potential of Shrouded Micro Wind Turbine. Proceedings of the International Conference on Science \& Engineering for Sustainable Development (2017), 340-351. doi: http://dx.doi.org/10.21013/ite.ICSESD201732

(C) International Conference on Science \& Engineering for Sustainable Development\& The Institution of Engineers (India).

\section{(cc) EY-NC}

This work is licensed under a Creative Commons Attribution-Non Commercial 4.0 International License subject to proper citation to the publication source of the work.

Disclaimer: The conference papers as published by the Institute of Research Advances (IRA) are the views and opinions of their respective authors and are not the views or opinions of the IRA. The IRA disclaims of any harm or loss caused due to the published content to any party. 


\section{ABSTRACT}

The growing demand for electrical energy for industrial and domestic use, coupled with the limited amount of available fossil fuel reserves and its negative effects on the environment, have made it necessary to seek alternative and renewable energy sources. The use of renewable energy is promoted worldwide to be less dependent on conventional fuels and nuclear energy. Therefore research in the field is motivated to increase efficiency of renewable energy systems.

This study aimed to study potential of micro wind turbine and velocity profile through shroud for low wind speeds. Although there is a greater inclination to use solar panels because of the local weather conditions, there are some practical implications that have place the use of solar panels in certain areas to an end. The biggest problem is panel stealing. Also, in some parts of the country the weather is more appropriate to apply wind turbines.

Thus, this study paying attention on the design of a new concept to improve wind turbines to be appropriate for the low wind speeds in India. The concept involves the implementation of a concentrator and diffuser to a wind turbine, to increase the power coefficient. Although the wind turbine was not tested for starting speeds, the realization of the shroud should contribute to improved starting of the wind turbine at lower wind speeds.

The configuration were not manufactured, but simulated with the use of a program to obtain the power production of the wind turbine over a range of wind speeds. These values were compared to measured results of an open wind turbine developed.

The most important topic at hand when dealing with a shrouded wind turbine is to find out if the overall diameter or the blade diameter of the turbine should be the point of reference. As the wind turbine is situated in a shroud that has a larger diameter than the turbine blades, some researchers believe that the overall diameter should be used to calculate the efficiency. The benefits of shrouded wind turbines are discussed.

Keywords: Potential of Micro Wind Turbine, Power Coefficient (Cp), Wind speed in shroud.

\section{Introduction}

\section{A. Global Energy Deficit}

In spite of numerous developments in energy technology, there are still over 1.3 billion people without access to electricity and 1 billion more only have intermittent access (see Figure.1below) [1]. The majority of this population depends on candles, kerosene lanterns, or biomass cook stoves to fulfill the basic needs of nutrition, warmth and light. In addition to their lower efficiencies, these energy sources can release damaging toxins and pose dangers to children who may either burn themselves or swallow toxic fuel stored in soft drink bottles. Beyond household needs, there is an increasing energy demand in developing countries to provide water, health care and education. For these reasons, lack of access to electricity is one of the clearest indications of a country's poverty status. 


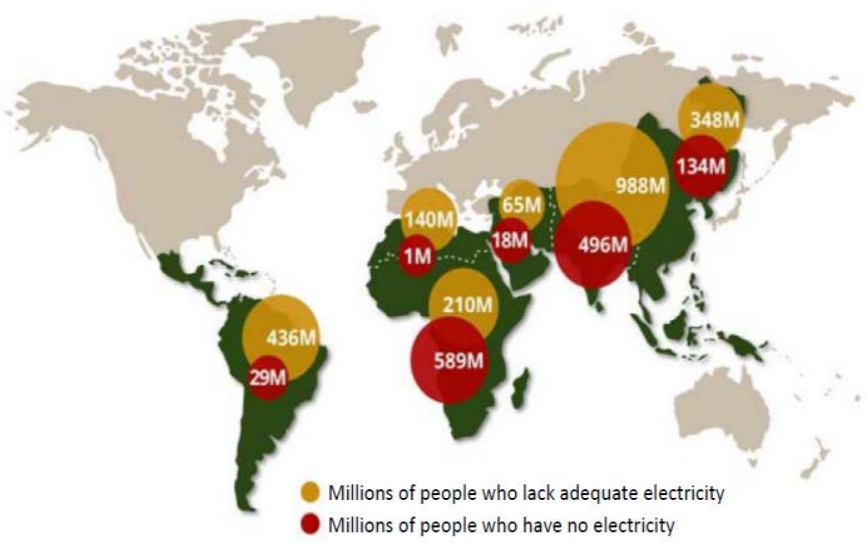

Figure 1: Global energy shortfall represented by region [2]

Conventionally, electrical energy is derived from conventional sources such as fossil fuels or nuclear energy. In these systems, electrical energy is generated by a large power plant and transmitted over long distances through distribution lines. While this may be the status quo, there are numerous consequences to using these energy sources. Not just are fossil fuels rapidly depleting as a resource, but the process of converting this source into electricity releases green house gases and adversely influences both the quality and availability of water. Nuclear power poses its own threats as it continuously releases dangerous radiation and has been linked to increasing cancer occurrences. In current decades, there has been a growing effort to obtain energy from more sustainable sources, such as hydroelectric plants or solar panels. While they are less harmful to the health of the environment and population, these sources demand either advanced machinery or specialized materials to construct. The greater part of the world population without access to electricity lives in rural areas where there is restricted access to the specific parts and materials needed to construct technologies such as solar panels. Moreover, they lack the capacity to build large dams for hydroelectric plants.

\section{B. Potential of Small Wind Turbines}

As a substitute, wind turbine technology may provide electricity in these rural locations. In particular, small wind turbines are an smart option for developing markets that at present lack electricity or are energy undersupplied. As a general instruction, Micro wind turbines are classified up to $1 \mathrm{~kW}$. Micro wind turbines have many benefits. They are easy and quick to install as they come in small sizes and have a lower construction lead time than extending the utility grid lines. Small wind turbines can operate for extended periods without attention; with only a few moving parts, these systems have very low maintenance requirements compared to other energy options. Additionally, small wind turbines are not difficult to produce. In this context, local built-up is often a suitable option for developing countries that could, in turn, stimulate local economic development and lower production costs. Wind systems replace existing household expenditures for kerosene, candles and dry-cell batteries. Finally, wind systems require little to no water to operate and do not contribute greenhouse gases or other toxins to the environment. Figure 2 illustrates the growing cumulative ability of small wind power across the globe. 


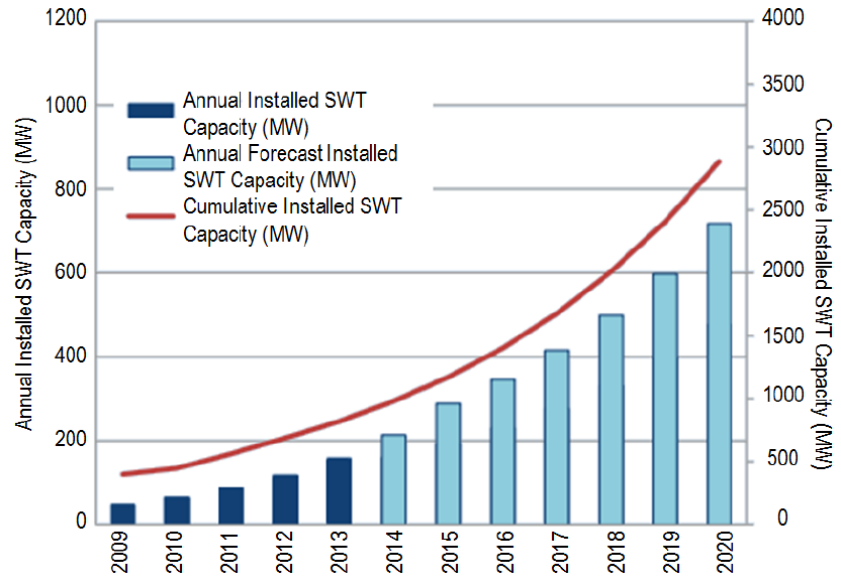

Figure 2:Small wind turbine worldwide installed capacity and forecast [3]

There are about 330 companies in 26 countries manufacturing small wind turbines, and the global market for small wind technologies is forecast to more than double between 2010 and

2015, getting USD 634 million. The installed capacity could increase threefold in the same period [4]. Much of this growth will take place in developing and emerging markets.

C. Design Rationale

While small wind turbines are associated with numerous benefits, their market penetration and social impact still faces certain limitations. Since wind turbines operate in as pecified ideal wind velocity range, locations with lower or unpredictable wind speeds are deemed unsuitable for small wind turbine installation. Moreover, locations that are capable to justify an investment in small wind turbines often find that their energy demand quickly increases and that energy yield of the wind turbine is no longer sufficient. In these cases, a reliance on dangerous energy such as diesel persists. This project is aimed at developing a solution that will help rural communities both justify a wind turbine installation and contain growth in energy demand. Figure 3 illustrates the annual frequency of wind speeds collected from a rural Nicaraguan village along with the corresponding energy yield of a wind turbine operating at that speed in megawatt-hours.

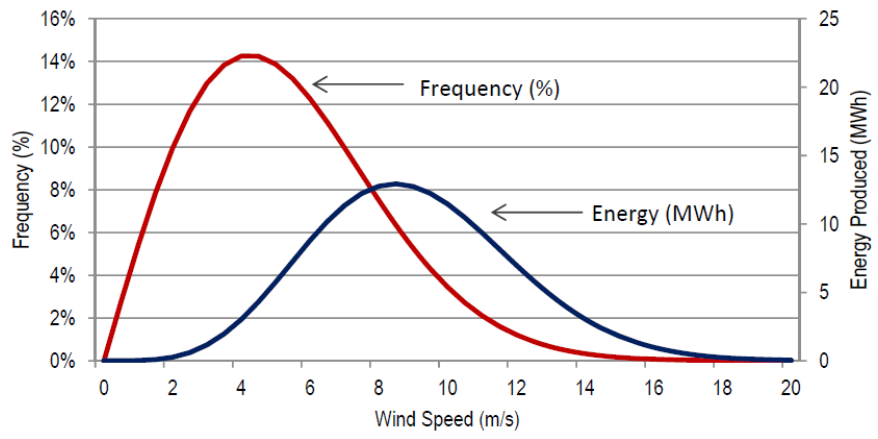

Figure 3: Frequency and energy yield of wind speeds [5]

Equally, Figure 4 models how the annual energy yield would be prejudiced by an increase in the frequency of higher wind speeds. This drastic energy boost is connected with a adjusting the mean annual wind speed from about $5.11 \mathrm{~m} / \mathrm{s}$ to about $7.67 \mathrm{~m} / \mathrm{s}$, a factor of 1.5 . 


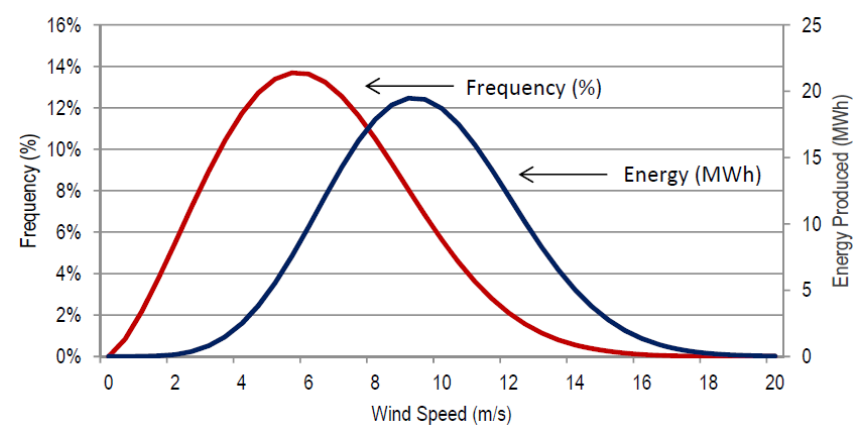

Figure 4: Frequency and energy yield of wind speeds with shroud

Even a slight increase in the frequency of higher wind speeds could result in enough energy yield to justify the construction of a small wind turbine. By revisiting small wind turbine technology and executing design modifications that increase the local incoming velocity, small wind power can become a more reliable and easily reached source of electricity for up to 2.3 billion people across the globe.

\section{Shrouded Wind Turbine}

\section{A. Generating High Output Power with Wind-lens Technology}

A new advance in wind technology is the wind lens. It acts as a diffuser, mounted behind the wind turbine, to generate a lower pressure area resulting in increased wind speeds through turbine. The diffuser augmented wind turbine (DAWT) was designed for use on a $5 \mathrm{~kW}$, three blade wind turbine that was to be applied on the shore of Hakata Bay in Japan [8]. Initial tests were performed in order to see whether a nozzle or diffuser would better amplify wind speeds and, between the two different designs, the diffuser performed appreciably better. The data shows that for the prototypes they construct, the high pressure area in the nozzle prevented significant flow through the turbine. This prompted the building of a model that would increase the wind velocity through the wind turbine that included a minor inlet shroud and a diffuser with a brim. A low-pressure region is generated at the rear the brim as vortices are produced. After this general design, four different designs were created, each with a different cross-sectional area. With each of these models the repetitive design method was utilized in order to produce the greatest power coefficient.

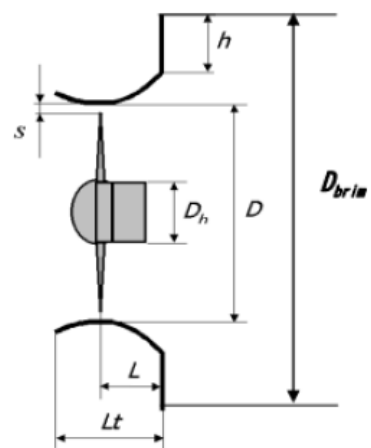

Figure 5: Diagram of wind-lens turbine [8] 
Wind Tunnel Tests on a Wind Turbine with Contractor and Diffuser Arrangement

Another system for increasing the wind speed through a wind turbine is a proportioned nozzle and diffuser. Nine different models were tested in which the main parameters investigated were the ratio of inlet to turbine diameters, the ratio of outlet to turbine diameters, and the length of transition from inlet to reduction and outlet [9]. Through the use of different geometric variations and CFD modeling, it was determined that a mirrored system where the inlet corresponding the outlet would produce the best results. In order to best investigate the data from modeling and testing, the energy in the airflow and the ratio between energy at the inlet and energy at the turbine blades was calculated by

$$
\begin{aligned}
& W=1 / 2 \rho A U^{3}, \\
& \frac{W_{2}}{W_{1}}=\frac{\rho_{2} A_{2} U_{2}{ }^{3}}{\rho_{1} A_{1} U_{1}{ }^{3}}=\left(\frac{U_{2}}{U_{1}}\right)^{2}
\end{aligned}
$$

where $\mathrm{W}$ is the wind energy available, $\rho$ is the density of air, $\mathrm{A}$ is the cross-sectional area, and $\mathrm{U}$ is the velocity of the air. Along with their design, data from the modeling and wind tunnel testing is provided. This data gives the differences in power output from the turbine when provided with a stable wind speed.

\section{B. Small-Scale Wind Energy Portable Turbines (SWEPT)}

Not simply is there growth in the wind industry relating to the power production of wind turbines, but also related to the usefulness and portability of turbines. This development of a very small and movable turbine with the combination of a shroud attachment shows that the improvement of wind speeds can be used in many different conditions, large or small [10]. In addition, SWEPT shows that researchers are continually finding ways to improve and increase the effectiveness and applicability of wind turbines.

\section{CFD Analysis for Optimization of Diffuser for a Micro Wind Turbine}

In the hope of reducing the pressure at the outlet of the diffuser even more, the effect of a flange around the outlet and its angle has been investigated. Three different setups were tested: a diffuser without flange, a diffuser with a vertical flange, and a diffuser angled back $10^{\circ}$ [11].From the tests, it was concluded that while the diffuser without a flange increases wind speeds through the turbine by $18.57 \%$, it does not compare with the effects of adding up a flange. When the diffuser is vertically flanged, wind speeds are enlarged by $34.28 \%$ and when the flange is angled $10^{\circ}$, speeds are increased by $40.3 \%$. Through a reasonably simple test, it was proven that by angling the flange, speeds are appreciably affected.

\section{Characteristics of a greatly Efficient Propeller Type Small Wind Turbine with a Diffuser}

Definite aspects of wind turbine diffusers were researched in 2006 in order to find an optimal design [12]. One of these characteristics is the angle at which the diffuser opens up from the slender area to the outlet. The data collected shows that the ideal expansion angle, the one that provides the greatest speed ratio, is an angle of $6^{\circ}$. The flange height was also dealt as a feature of the diffuser, which was found to have a negligible effect on the wind speed ratio as long as the flange was a tenth of the diameter of the turbine. 
Matsushima et al. [12] presented a diffuser with a brim attached to its outlet. The brim increases the separation at the back of the diffuser and reduces the pressure near the outlet of the diffuser, at the back of the brim (this effect is the same as pressure drag, as earlier defined in section). Figure 6 shows a diffuser with brim and inlet shroud (in this design there was no in let shroud). The example presents the large amount of separation at the rear of the shroud. This reduces the static pressure in this part of the diffuser. For this study a CFD simulation of a diffuser with an inlet diameter of $1 \mathrm{~m}$, a total length of $2 \mathrm{~m}$ to $4 \mathrm{~m}$, a brim height of $100 \mathrm{~mm}$ to $500 \mathrm{~mm}$ and the angle of the diffuser between $0^{\circ}$ and $12^{0}$ was arranged by Matsushima et al.(2005). The simulation was done without a wind turbine. The air velocity ratio (between the free wind speed and inlet air speed) increased stridently from a diffuser angle of $0^{0}$ to $4^{0}$ and reached a maximum at $6^{0}$. It was found that the inlet velocity ratio did not increase at a brim height of more than a $100 \mathrm{~mm}$. An inlet velocity ratio of 1.7 was found with these dimensions.

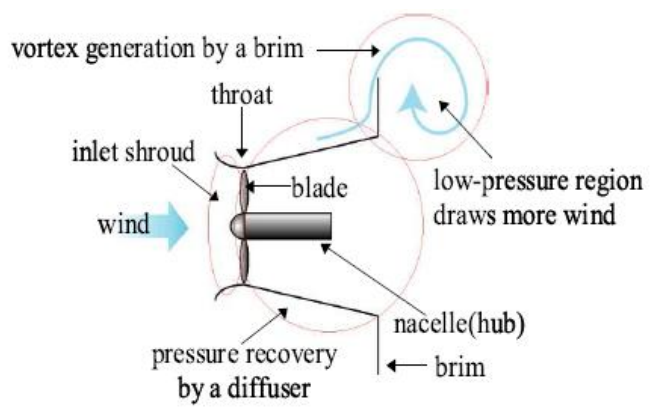

Figure 6: DAWT with inlet shroud and brim [13]

The trial product built by Matsushima et al. had a diffuser length of $2 \mathrm{~m}$, diffuser angle of $4^{0}$ and a brim height of a $100 \mathrm{~mm}$. A wind turbine with five blades was incorporated inside the diffuser. The same type of wind turbine without a diffuser and brim was constructed near this shrouded wind turbine to compare the energy output over a certain period of time. Some troubles were experienced with the adjusting of the field device to the wind direction. Thus, the researchers fixed the bare wind turbine and shrouded wind turbine in the direction where the frequency distribution of the wind was high. The total energy generated for the entire day was measured and it was found that the shrouded wind turbine produced 1.65 times more energy than the conventional wind turbine. Abe [14] did a CFD exploration and found some important features for a diffuser with a brim. The performance of the wind turbine depends strongly on the loading coefficient and the angle of the diffuser. This significantly affects the nature of the separation in the diffuser.

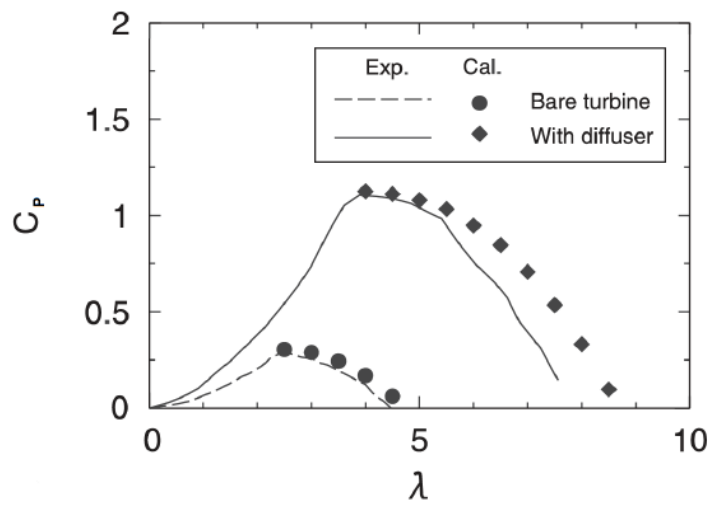


Figure 7: Power coefficient / tip speed ratio of a wind turbine with brim tested by Abe et al.[14] From the investigation of Abe (2004) it was also clear that the loading coefficient must be much smaller than that of a normal HAWT's. If the loading coefficient is much high it will reduce velocity at the entrance and a higher pressure discontinues over the wind turbine area. Therefore it will be possible to have a higher pressure drop over the area of the wind turbine with a lower air velocity or a lower pressure drop with a higher air velocity. The second seems to increase the energy output of the turbine in this type of configuration. From various results obtained in the CFD investigation by Abe (2004), it became clear the optimum loading coefficient for every variation of the diffusers angle, length and brim height needs to be determined. The CFD investigation was performed with wind tunnel experiments by Abe et al. [14]. The Brim (200mm) was substantially greater than the brim of Matsushima et al. (2005) and the diffuser angle was also increased. The wind turbine used in the experiment had a diameter of 400mm. Figure 7 prove that the power coefficient tof the wind turbine with the diffuser was substantially higher than the bare wind turbine. The energy output is much higher than the diffuser with brim of Matsushima et al. (2005), this can be devoted to the larger diffuser angle and brim. From the investigation it was also found that the shrouded wind turbines' peak performance was at a higher tip speed ratio than that of the open wind turbine. Figure 7 also shows that the experimental data and CFD modeled power coefficient results correspond well.

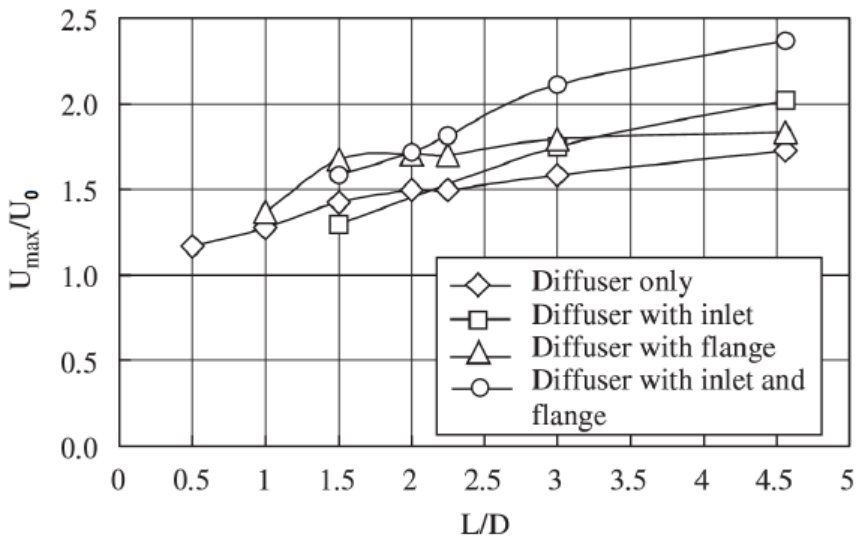

Figure 8: Velocity increase with different configurations of components and length ratio's (Ohyaet al.

Ohya et al. [15] did some experiments with various configurations of components. The results are presented in Figure 8. The total length divided by the inlet diameter is denoted on the horizontal axis of the graph. The free wind speed is $\mathrm{U}_{0}$ and $\mathrm{U}_{\max }$ is the maximum airspeed as obtained at the throat. It is evident that the configuration with diffuser, brim and inlet shroud offers the best velocity ratio. Another important feature to be taken into account is the length of such a pattern. Findings proved that the air speed inside increases when the diffuser is lengthened. However, carefulness to apply a very long structure is emphasized as it will have realistic constraints, for example when to be constructed on a tower. For the field test an 8mtower was erected by Ohya et al. (2008) and a diffuser inlet diameter of 0:72m was decided upon with a total length of $0: 9 \mathrm{~m}$ and brim height of $0: 36 \mathrm{~m}$ was applied. The practical and calculated results show a power coefficient $\mathrm{Cp}=1.4$ compared to a $\mathrm{Cp}=0.35$ for the open turbine. Ohya et al. (2008) also deviced and constructed a number of compact shrouded wind turbines with the 
same configuration as above with total length divided by the inlet diameter of 0.22 and a total diameter of $2.5 \mathrm{~m}$. The wind turbines were rated as $5 \mathrm{~kW}$. A $\mathrm{Cp}=0.54$ was obtained when the total outer diameter (brim included) was used to find the power coefficient. This is still an exceptional performance as most wind turbines on the market only have a power coefficient of $\mathrm{Cp}=0.4$.

From the field devices that were tested it could be observed that the Cp value of a DAWT was larger. This is also the case even though the outer diameter of the angle is used as reference and not the blade maximum diameter.

The numerical investigation by Abe and wind tunnel experimental results by Abe et al. also discovered the advantages of a shrouded wind turbine compared to an open wind turbine. This arrangement could thus be used to improve the drawing out of energy from low speed wind for more efficient power production.

\section{E. Concentrators}

Concentrated wind will increase the power yield in relation with the rotor-swept area [16]. A wind turbine in the concentrator will come across a higher air speed and rotate at a higher revolution per minute. This wind turbine will also start rotating at a lower free wind speed as the concentrator enhances the air speed. Therefore, the concept of a concentrator should be advantageous. Recent work, as will be investigated further, will give some insight into this idea. The experimental work with concentrators by Shikha et al. [17] found that a concentrator with an outlet to inlet ratio of 0.15 displays the best increase of 4 to 4.5 times the free windspeed, at the outlet. If the increase was found with continuity and incompressibility (at low Reynolds numbers) the speed at the outlet should have been 6.7 times that of the free wind speed. From this it can be accomplished that some of the mass flow tends to avoid the concentrator. This is a result of the abrupt increase in area at the outlet of the concentrator, skin friction drag and pressure drag. These losses create a obstacle to flow while a free wind stream usually evades such restrictions. Ohya et al. [15] also experimented with concentrators and the conclusion is presented in Figure 9 which confirms the results of Shikha et al. [17]. Ohya et al. [15] found that the wind tends to avoid the nozzle-type model.

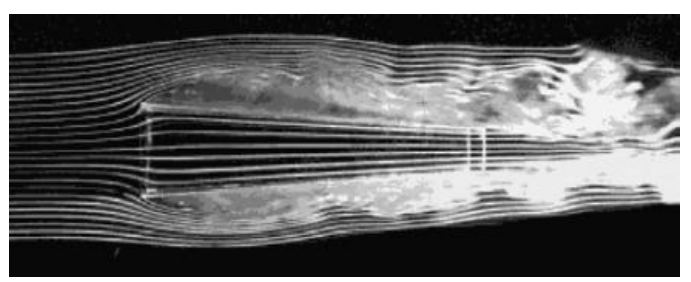

Figure 9: Concentrator in a wind tunnel [15]

Recently, concentrators are mostly used in combination with vertical axis wind turbines. The air flow is intensed and deflected away from the one side of the horizontal blades, thus reducing drag and increasing the power output of the wind turbine [18].However, for HWAT's there is an only new development with a concentrator in conjunction with a diffuser (Figure 10). As the diffuser is fixed to the outlet of the concentrator, the losses of energy that happen with the sudden increase in area are avoided. Recently did CFD simulations and wind tunnel tests on a concentrator with diffuser configuration [19]. When the wind turbine was fitted into the shroud the captured energy amplified with $43 \%$ for the same free wind speed. This emphasizes the significance of a shrouded wind turbine. It is further proposed that the configuration should rather be build-in or mounted on a structure than mounted on a pole. Wang et al. (2008c) 
concluded after extensive research that an existing wind turbine cannot be used in the shroud. The need was confirmed for newly devised blades and hub to set the conditions in the shroud.

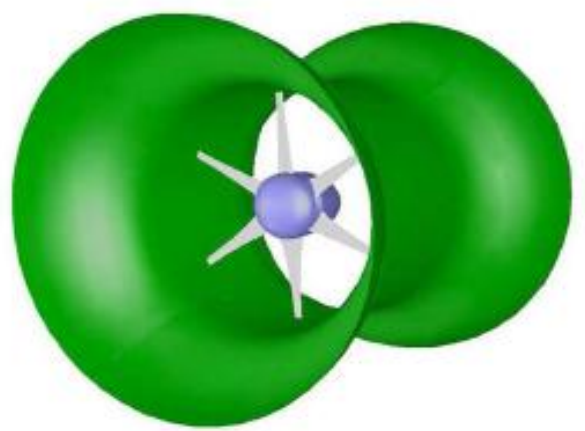

Figure 10: Concentrator, Diffuser type of wind turbine [19]

A new advance in wind technology is the wind lens. It acts as a diffuser, mounted at the back of the wind turbine, to create a lower pressure area resulting in increased wind speeds throughout turbine. The diffuser augmented wind turbine (DAWT) was devised for use on a $5 \mathrm{~kW}$, three blade wind turbine that was to be applied on the shore of Hakata Bay in Japan [8]. Initial tests were performed in order to see whether a nozzle or diffuser would further increase wind speeds and, between the two different designs, the diffuser performed drastically better. The data indicates that for the prototypes they built, the high pressure area in the nozzle prevented significant flow through the turbine. This encouraged the construction of a model that would increase the wind velocity through the wind turbine that added a slight inlet shroud and a diffuser with a brim. A low-pressure region is generated behind the brim as vortices are formed. After this common design, four different designs were formed, each with a different crosssectional area. With each of these models the iterative design process was used in order to produce the greatest power coefficient.

The eventual objective of this paper is to provide information on the velocities through the turbine of shroud design using CFD (computational fluid dynamic) modeling. Wind turbines have a specified wind speed operating range at which they generate energy at higher efficiencies. A successful shroud model increases the incoming wind speeds with a nozzle/diffuser shroud mounted to the turbine to amend the wind flow convergence. Particularly, the shroud increases wind speeds through the turbine, is structurally sound, and minimizes drag.

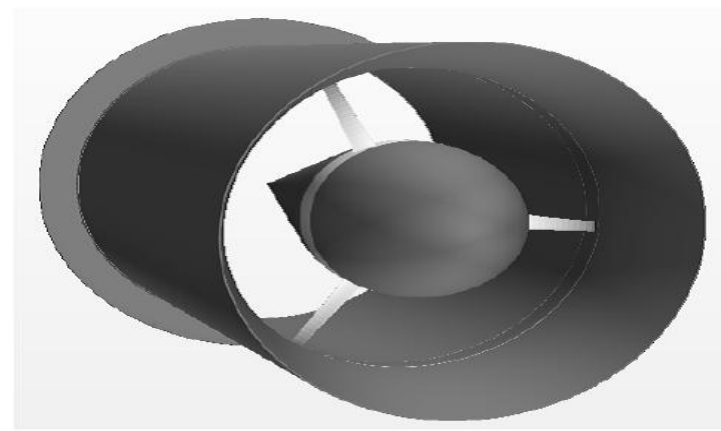

Figure 11: Model of Shrouded wind turbine 


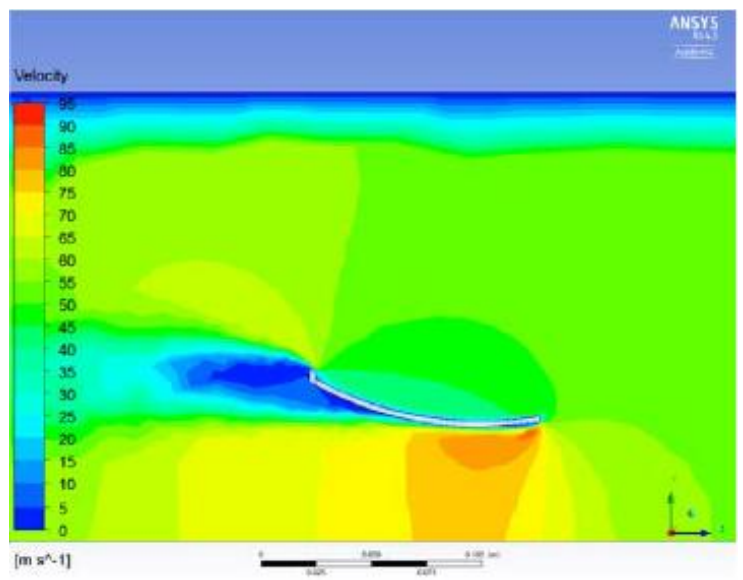

Figure 12: Cross sectional view of a shroud geometry presenting wind velocity contours around shroud

In order to simplify the calculations done and increase the detail of the mesh by the CFD analysis, only a quarter of the geometry was modeled assuming the flow would be symmetrical through the shroud. The maximum achievable wind speeds in Santa Clara University's wind tunnel are roughly $55 \mathrm{~m} / \mathrm{s}$. Because of this, the CFD model was run presuming an inlet velocity of $55 \mathrm{~m} / \mathrm{s}$. The most ideal material for the full size product is still unclear. However, the scaled models are 3D printed in ABS plastic, so for more accurate comparison, the CFD analysis used a similar type of plastic to model the shroud. However, in the case of examining flow through the shroud, the type of the material used is of comparatively low significance.

This software was useful in that it allows a visual comparison of how geometric factors affect the presentation of the shroud through the analysis of velocity and pressure curves. For example, Figure 12 displays quarter view pressure contours of two shrouds geometries that differ only in that the one on the right is curved.

\section{Conclusion}

The paper found out one approach to improve the utility of small wind turbines. By adding a flanged nozzle/diffuser shroud, the wind velocity at the blades is in the vicinity enhanced, thereby improving the energy generation at lower wind speeds. The design of the shroud was performed through CFD modeling in ANSYS Fluent by dividing geometric factors and determining their effect on the performance. The most significant factor on the performance of the shroud was determined to be the length of the diffuser. Number of attempts was made to model the result of rotating turbine blades in ANSYS but none were able to establish this accurately. A shroud design that met the design and performance criteria was selected and a scale model was 3D presented for wind tunnel testing at Santa Clara University. The factor by which wind turbine power generation was increased by the integration of the shroud was measured to be3.18, which is connected with a wind speed increase of 1.47. The added drag force on the turbine post due to the shroud was also measured in order to establish an experimental drag coefficient of 0.906 . When scaled to full-size, this raises concerns for the structural reliability of the turbine base. Further structural analysis will be required as the turbine used for full scale accomplishment is selected. Pressure measurements along the length of the shroud during wind tunnel testing established the CFD modeling results. This motivates the use of ANSYS Fluent as a tool to model the system at a larger scale. 


\section{References}

[1] World Energy Outlook. International Energy Agency, 2013, Web.

[2] World Energy Outlook. International Energy Agency, 2012, Web.

[3] Small Wind World Report 2014. : World Wind Energy Association, 2014. Web.

[4] The Potential of Small and Medium Wind Energy in Developing Countries. A Guide for Energy Sector Decision-makers. Publication. Alliance for Rural Electrification, 2012,Web.

[5] GL Garrad Hassan. : GL Garrad Hassan, Onshore Wind Services. GL GarradHassan, Sept. 2012. Web.

[6] "Bergey 10kW." Bergey. Bergey, Web. <http://bergey.com/documents/2012/05/excel-10brochure.pdf>.

[7] BERGEY Excel $10 \mathrm{KW}$ in Action. N.d. Iowa Wind Turbines. Web.<http://www.iowawindturbines.com/>.

[8] Ohya, Yuji, and Takashi Karasudani. "A Shrouded Wind Turbine Generating High OutputPower with Wind-lens Technology." Energies 3.4 (2010): 634-49. Print.

[9] Fletcher, J. "Wind Tunnel Tests on a Wind Turbine with Contractor and DiffuserArrangement." POWERENG, 12 Apr. 2007. Web. 10 Oct. 2013.

[10] Kishore, Ravi. "Small-Scale Wind Energy Portable Turbines (SWEPT)." Journal of WindEngineering and Industrial Aerodynamics, Web. 10 Oct. 2013.

[11] Kale, Sandip A. "CFD Analysis for Optimization of Diffuser for a Micro Wind Turbine.". Web. 10 Oct. 2013.

[12] Matsushima, Toshio. "Characteristics of a Highly Efficient Propeller Type Small Wind Turbine with a Diffuser." Renewable Energy, 2006. Web. 10 Oct. 2013.

[13] Matsushima, T., Takagi, S. \& Muroyama, S. (2005), 'Characteristics of a highly efficient propellertype small wind turbine with a diffuser', Renewable energy xx, 1-12.

[14] Abe, O. (2004), "An investigation of flow fields around flanged diffusers using cfd", Journal of windengineering and industrial aerodynamics 92, 315-330.

[15] Ohya, Y. \& Karasudani, T. (2010), "A shrouded wind turbine generating high output power withwind-lens technology.", Energies 3, 634-649.

[16] Hau, E. (2006), Wind turbines. Fundamentals, Technologies, Application, Springer.

[17] Shikha, S., Bhatti, T. \& Kothhari, D. (2005), “Air concentrating nozzles: a promising option forwind turbines", Int. J. Energy Technology and Policy 3, 394-412.

[18] Orosa, J., Garcia-Bustelo, E. \& Oliveira, A. (2009), "Low speed wind concentrator to improve windfarm power generation", Industrial Electronics".

[19] Wang, F., Bai, L., Fletcher, J., Whiteford, J. \& Cullen, D. (2007), Wind tunnel tests on a wind turbine with concentrator and diffuser arrangement, Technical report, POWERENG. 